RAD Conference Proceedings, vol. 4, pp. 1-6, 2020

ISSN 2466-4626 (online) | DOI: 10.21175/RadProc.2020.01

www.rad-proceedings.org

\title{
NANODIAMONDS AND CARBON NANOTUBES AS PERSPECTIVE CARRIERS OF BISMUTH ISOTOPES FOR NUCLEAR MEDICINE
}

\author{
Andrey G. Kazakov, Bogdan L. Garashchenko, Julia S. Babenya, \\ Milana K. Ivanova, Sergey E. Vinokurov*, Boris F. Myasoedov
}

Vernadsky Institute of Geochemistry and Analytical Chemistry of the Russian Academy of Sciences, Radiochemistry

Laboratory, Moscow, Russia

\begin{abstract}
Currently, a wide range of nanomaterials, including carbon nanomaterials (CNMs), are being investigated as possible carriers of radionuclides for nuclear medicine as a part of radiopharmaceuticals (RPs). The present work considers the possibility of using nanodiamonds (ND) and multi-walled carbon nanotubes and their derivatives to act as a potential basis for RPs containing bismuth which have radioisotopes 212,213 Bi for targeted alpha-therapy. To study this, the kinetics of Bi(III) sorption onto selected CNMs in aqueous media with different $p H$, as well as Bi(III) desorption from these samples by a solution of fetal bovine serum at $37{ }^{\circ} \mathrm{C}$ were investigated. The optimal conditions for the sorption of Bi(III) onto the studied CNMs were found; it was shown that oxidized ND was the most promising carrier for bismuth isotopes: sorption at $\mathrm{pH} 3$ to 7 for this sample was close to quantitative, and desorption in 120 min does not exceed $5 \%$. The cytotoxicity of CNMs was investigated in the standard MTT test, it was shown that $L C_{50}$ for all studied samples was $>200 \mu \mathrm{g} / \mathrm{mL}$.
\end{abstract}

Keywords: Carbon nanomaterials; bismuth radioisotopes; sorption and desorption; nanodiamonds; multi-walled carbon nanotubes; carriers for nuclear medicine; targeted alpha-therapy

\section{INTRODUCTION}

Nowadays, nanomaterials in general and carbon nanomaterials (CNMs) in particular are promising substances for use in a huge number of fields of technology and science and attract the attention of an increasing number of researchers due to the unique physicochemical properties [1-4]. Uniqueness is primarily associated with the high surface area of such materials, as well as with the possibility of its directed functionalization by various groups or substances $[5,6]$.

The variety of possibilities for modifying the surface of the CNMs allows to design materials with the properties for different tasks solutions [7-9]. Thus, the ability to bind metal cations, their complexes, and various organic molecules to the surface of the CNMs makes it possible for the CNMs to be considered as a basis for RPs [10, 11]. Different CNMs includes ND [12, 13], graphene and its oxide [14-19], carbon nanotubes [20-26] - are considered as promising carriers of various radioactive isotopes and drugs for nuclear medicine for the diagnosis and treatment of cancer.

One of the most effective methods of killing cancerous tumors is targeted alpha-therapy [27-30]. In this method, an alpha-emitting radionuclide is delivered to tumors and selectively binds to tumor cells using specially chosen molecule vectors or carriers; and after these alpha particles destroy the tumor without damaging the surrounding healthy tissues due to a short emitting range. Various nanoparticles can act as such carriers, however, information on the use of CNMs as carriers of radionuclides for targeted alpha-therapy is limited [31-34].

Among the radionuclides used in targeted alphatherapy, there are two promising bismuth isotopes ${ }^{212} \mathrm{Bi}$ $\left(36 \%\right.$ a, 64\% $\left.\beta-, \mathrm{T}_{1 / 2}=60.6 \mathrm{~min}\right)$ and ${ }^{213} \mathrm{Bi}$ (complex $\alpha$ and $\beta^{-}$decays chain, $\mathrm{T}_{1 / 2}=45.6 \mathrm{~min}$ ) [35]. The preparation of both isotopes is well studied: ${ }^{212} \mathrm{Bi}$ is isolated from ${ }^{212} \mathrm{~Pb} /{ }^{212} \mathrm{Bi}$ generators [36], and ${ }^{213} \mathrm{Bi}-$ is from ${ }^{225} \mathrm{Ac} /{ }^{213} \mathrm{Bi}$ generators, where ${ }^{225} \mathrm{Ac}$ undergoes four fast alpha decays [37]; the use of both generators in vivo is also being studied [35, 38]. The half-lives of both isotopes are slightly less than optimal for alpha-therapy, but nevertheless they allow ${ }^{212} \mathrm{Bi}$ and ${ }^{213} \mathrm{Bi}$ to be used in the case of rapid delivery of RPs with those isotopes to tumors [39]. Usually, ${ }^{212} \mathrm{Bi}$ and ${ }^{213} \mathrm{Bi}$ are chelated by DOTA (1,4,7,10-tetraazacyclododecane-1,4,7,10tetraacetic acid) derivatives and bind to antibodies, while studies of ever new methods of their use in targeted alpha-therapy have been conducted over the past decades [40].

In our recent work, the ability of CNMs to sorb bismuth was demonstrated [34]. The aim of the present research is a detailed study of the dependence of sorption and desorption of $\mathrm{Bi}(\mathrm{III})$ onto the most promising CNMs (ND and multi-walled carbon nanotubes (MWCNT)) in various media to search for optimal conditions for the synthesis of bismuth based RPs for further possible use in targeted alpha-therapy.

*vinokurov.geokhi@gmail.com 
A. Kazakov et al., Nanodiamonds and carbon nanotubes..., RAD Conf. Proc., vol. 4, 2020, 1-6

\section{MATERIALS AND METHODS}

\subsection{CNMs preparation and characterization}

In our work we used commercial samples of ND (SKTB Tekhnolog, Russia, trademark UDA-TAN) and MWCNT (NanoTekhTsentr Ltd, Russia) and also oxidized ND (namely, oxND) and hydrogenated MWCNT (namely, hydMWCNT), prepared in our experiments. To obtain oxND and hydMWCNT, following reactions (1) and (2) were carried out. All chemical reagents used in the work had purity not lower than "chemically pure".

$$
\begin{aligned}
& \mathrm{ND} \stackrel{\mathrm{H}_{2} \mathrm{SO}_{4} / \mathrm{HNO}_{3}(3: 1),\left(120^{\circ} \mathrm{C}, 24 \mathrm{~h}\right)}{\longrightarrow} \text { oxND } \\
& \text { MWCNT } \stackrel{10 \% \mathrm{H}_{2}+90 \% \operatorname{Ar}\left(800^{\circ} \mathrm{C}, 5 \mathrm{~h}\right)}{\longrightarrow} \text { hydMWCNT }
\end{aligned}
$$

Earlier we made a characterization of commercial and modified CNMs samples used in present research $[34,41,42]$. Table 1 summarizes the main characteristics of the CNMs used, and Fig. 1 shows the SEM images of ND and MWCNT.

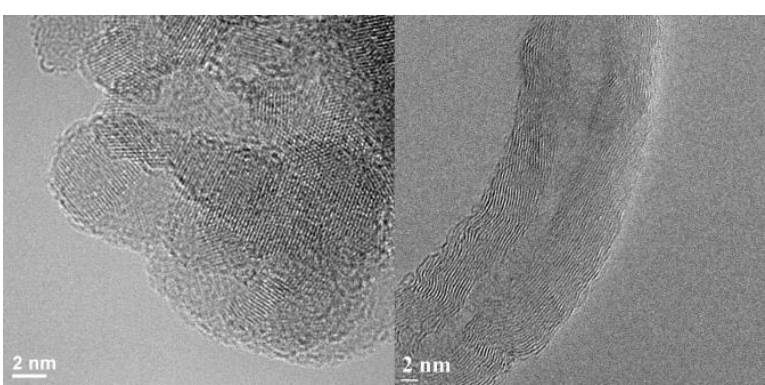

Figure 1. SEM images of ND (left) and MWCNT (right) which are similar to oxND and hydMWCNT, respectively [34].

The cytotoxicity of the studied CNMs was investigated in a standard MTT test, for which CNMs were suspended in phosphate buffered saline (PBS) with a nanoparticles content of $1,5,10,50,100$, $200 \mu \mathrm{g} / \mathrm{mL}$. The MTT test was performed on mononuclear cells of healthy donors as well as on Blymphoblastic leukemia cells; in each case cells from three different donors were taken.

\subsection{Detection of Bi(III)}

To determine sorption behavior of Bi(III), gammaemitting isotope ${ }^{207} \mathrm{Bi}\left(\mathrm{T}_{1 / 2}=31.55 \mathrm{y}\right)$ was used in all experiments which were conducted in a glove box.

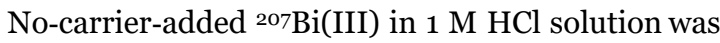
obtained from Cyclotron Co. Ltd. (Obninsk, Russia) with volume activity $2.37 \mathrm{MBq} / \mathrm{mL}$, radionuclidic purity more than $99.7 \%$ and content of inactive metal impurities no more than $1 \times 10^{-6} \mu \mathrm{g}$ per $1 \mathrm{~Bq}$ of ${ }^{207} \mathrm{Bi}$.

The ${ }^{207} \mathrm{Bi}$ content in all studied solutions was determined by gamma-ray spectrometry using the $569.7 \mathrm{keV}$ line on a spectrometer with a high-purity germanium detector GC 1020 (Canberra Ind, Meriden, CT, USA).

\begin{tabular}{|c|c|c|c|c|}
\hline $\begin{array}{l}\text { Characteris- } \\
\text { tics }\end{array}$ & ND & oxND & MWCNT & $\begin{array}{l}\text { hydMWC } \\
\text { NT }\end{array}$ \\
\hline $\begin{array}{l}\text { Particle size } \\
\text { of the } \\
\text { original } \\
\text { samples } \\
(\mathrm{nm})\end{array}$ & $3-10$ & $3-10$ & $\begin{array}{c}\text { Length }> \\
2 \cdot 10^{4} \\
\text { Diameter } \\
-30 \\
\text { Wall } \\
\text { thickness } \\
5-10\end{array}$ & $\begin{array}{c}\text { Length }> \\
2 \cdot 10^{4} \\
\text { Diameter } \\
-30 \\
\text { Wall } \\
\text { thickness } \\
5-10\end{array}$ \\
\hline $\begin{array}{l}\text { The total } \\
\text { content of } \\
\text { impurities } \\
\text { according to } \\
\text { ICP-MS, } \\
\mathrm{mg} / \mathrm{g}\end{array}$ & 1.4 & $\mathrm{n} / \mathrm{d}$ & 14.0 & $\mathrm{n} / \mathrm{d}$ \\
\hline $\begin{array}{l}\text { The main } \\
\text { impurities } \\
\text { (more than } \\
\text { o.1 mg/g) } \\
\text { and their } \\
\text { content, } \\
\mathrm{mg} / \mathrm{g}\end{array}$ & $\begin{array}{c}\mathrm{Fe}- \\
\mathrm{O} .538 \\
\mathrm{Ti}- \\
\mathrm{O} .459 \\
\mathrm{~K}- \\
0.156\end{array}$ & $\mathrm{n} / \mathrm{d}$ & $\begin{array}{c}\mathrm{Mo}- \\
6.88 \mathrm{o} \\
\mathrm{Co}- \\
5.830 \\
\mathrm{Al}- \\
\mathrm{o} .635 \\
\mathrm{Ni}- \\
0.156\end{array}$ & $\mathrm{n} / \mathrm{d}$ \\
\hline $\begin{array}{l}\text { Specific } \\
\text { surface area, } \\
\mathrm{m}^{2} / \mathrm{g}\end{array}$ & 240 & 250 & 160 & 155 \\
\hline $\begin{array}{l}\text { Elemental } \\
\text { composition } \\
\text { of the } \\
\text { surface } \\
\text { according to } \\
\text { XPS, \% }\end{array}$ & $\begin{array}{c}\mathrm{C}\left(\mathrm{sp}^{3}\right) \\
-92.3 \\
\mathrm{O}- \\
7.7\end{array}$ & $\begin{array}{l}\mathrm{C}\left(\mathrm{sp}^{3}\right) \\
-90.1 \\
\mathrm{O}^{-}- \\
9.9\end{array}$ & $\begin{array}{c}\mathrm{C}\left(\mathrm{sp}^{2}\right)- \\
99.0 \\
\mathrm{O}-1.0\end{array}$ & $\begin{array}{c}\mathrm{C}\left(\mathrm{sp}^{2}\right)- \\
99.4 \\
\mathrm{O}-0.6\end{array}$ \\
\hline $\begin{array}{l}\text { The size of } \\
\text { particles and } \\
\text { their } \\
\text { aggregates } \\
\text { in hydrosols, } \\
\text { nm }\end{array}$ & 100 & 95 & $\mathrm{n} / \mathrm{d}^{1}$ & $\begin{array}{c}150 \text { and } \\
650\end{array}$ \\
\hline $\begin{array}{l}\text { Amount of - } \\
\text { COOH } \\
\text { according to } \\
\text { titration, } \\
\mu \mathrm{mol} / \mathrm{g}\end{array}$ & 330 & 990 & $\mathrm{n} / \mathrm{d}$ & $\mathrm{n} / \mathrm{d}$ \\
\hline
\end{tabular}

Table 1. Characterization of commercial and modified CNMs

${ }^{1}$ impossible to determine by DLS if at least one of the linear particle sizes exceeds $1000 \mathrm{~nm}$

\subsection{Sorption and desorption experiments}

Initial ${ }^{207} \mathrm{Bi}$ radioactivity and concentration in each sample was $800 \mathrm{~Bq}$ and $1.9 \times 10^{-9} \mathrm{M}$.

Each experiment with ${ }^{207} \mathrm{Bi}$ sorption or desorption was repeated at least three times until converging values.

To obtain samples for sorption, aliquots of initial ${ }^{207} \mathrm{Bi}$ solution in $1 \mathrm{M} \mathrm{HCl}$ were diluted by double distilled water (to obtain solutions with $\mathrm{pH} \mathrm{1,2}$ and 3) or were evaporated to dryness in a glass beaker and then residues were diluted by solutions of $\mathrm{HCl}$ or $\mathrm{NH}_{3}$ to obtain solutions with $\mathrm{pH} 5$ or 7 ; $\mathrm{pH}$ was always controlled by pH-meter "Expert" (Econix-Expert Ltd, Moscow, Russia). Aliquots of ${ }^{207} \mathrm{Bi}$ solutions with established $\mathrm{pH}$ and aliquots of suspension of CNMs were successively added to the Eppendorf tube, with a total volume of $1 \mathrm{~mL}$ containing $100 \mu \mathrm{g}$ of CNMs (this amount was previously determined as sufficient for maximum sorption of $\mathrm{Bi}(\mathrm{III})$ [34]). The experiments were carried out at 25 (sorption) and $37^{\circ} \mathrm{C}$ (desorption); 
the temperature was controlled by a thermal shaker attachment (TS-100, Biosan, Latvia); rate of shaking was $1100 \mathrm{rpm}$. After sorption, the phases were separated by centrifugation for $15 \mathrm{~min}$ at $15,000 \mathrm{~g}$ (in preliminary experiments, it was shown that these conditions are sufficient for quantitative phase separation), $800 \mu \mathrm{L}$ of the supernatant were taken and the gamma spectrum was registered, comparing with the initial activity of the solutions before sorption.

The stability of the obtained 207Bi@CNMs conjugates was evaluated by studying desorption of ${ }^{207} \mathrm{Bi}$ in fetal bovine serum (FBS) which is a model blood plasma medium. For this, sorption was carried out for $15 \mathrm{~min}$ at $\mathrm{pH} 3$ for ND and oxND, at $\mathrm{pH} 5$ for MWCNT and hydMWCNT, and then samples were centrifuged. After it, the supernatant was removed, FBS was added to the sediment of CNMs, and the solution was agitated, placed on a shaker, then centrifuged again and the supernatant was again separated for further gamma-ray measurement.

\section{RESULTS AND DISCUSSION}

We studied the sorption of ${ }^{207} \mathrm{Bi}$ onto ND, oxND, MWCNT, and hydMWCNT from aqueous solutions with $\mathrm{pH} \mathrm{1,2,3,5}$ and 7, as well as the desorption of ${ }^{207} \mathrm{Bi}$ from all studied CNMs samples by FBS.

\subsection{Sorption of ${ }^{207}$ Bi onto CMNs}

It is well-known that $\mathrm{Bi}^{3+}$ in aqueous solutions has a high tendency to hydrolysis (solubility constant for $\mathrm{Bi}(\mathrm{OH})_{3}$ is $3 \cdot 2 \cdot 10^{-32}$, which determines the existence of polynuclear oxo- and hydroxocomplexes of various structure even in acidic solutions. The study of the dependence of $\mathrm{Bi}$ (III) sorption onto CNMs on the $\mathrm{pH}$ of the solution was an interesting and important task, since different compounds of Bi(III) exists in different solutions, which can affect sorption.

Studying the sorption of ${ }^{207} \mathrm{Bi}$ from aqueous solutions, it was found that the absence of sorption was observed onto all studied CNMs samples for $60 \mathrm{~min}$ at $\mathrm{pH}$ 1. The results of studying sorption at $\mathrm{pH} 2$ to 7 are shown in Fig. 2a-d. It was determined that with increasing $\mathrm{pH}$, the sorption value increases for all studied CNMs. Thus, at $\mathrm{pH} \mathrm{2,} \mathrm{sorption} \mathrm{onto} \mathrm{ND} \mathrm{and}$ oxND is 40 and $60 \%$; with an increase in $\mathrm{pH}$ to 3 , sorption onto these CNMs becomes more than $80 \%$, Fig. 2a,b. MWCNT and hydMWCNT do not sorb Bi(III) at $\mathrm{pH} 2$; sorption at $\mathrm{pH} 3$ is about $60-70 \%$ (Fig. 2c,d). Finally, at $\mathrm{pH} 5$ to 7 , the maximum sorption of ${ }^{207} \mathrm{Bi}$ is observed for all four CNMs and is 80 to $>95 \%$. It is also noticeable that the sorption of ${ }^{207} \mathrm{Bi}(\mathrm{III})$ onto all samples is characterized by fast kinetics - equilibrium occurs in 5-15 minutes.

\subsection{Desorption of ${ }^{207} \mathrm{Bi}$ by FBS}

To study the desorption of ${ }^{207} \mathrm{Bi}$ from CNMs, the FBS medium was chosen; the results are shown in Fig. 3. Data in Fig. 3 shows that the strongest binding of ${ }^{207} \mathrm{Bi}$ is observed for ND and oxND, for which desorption in 120 min was 19 and $7 \%$, respectively.
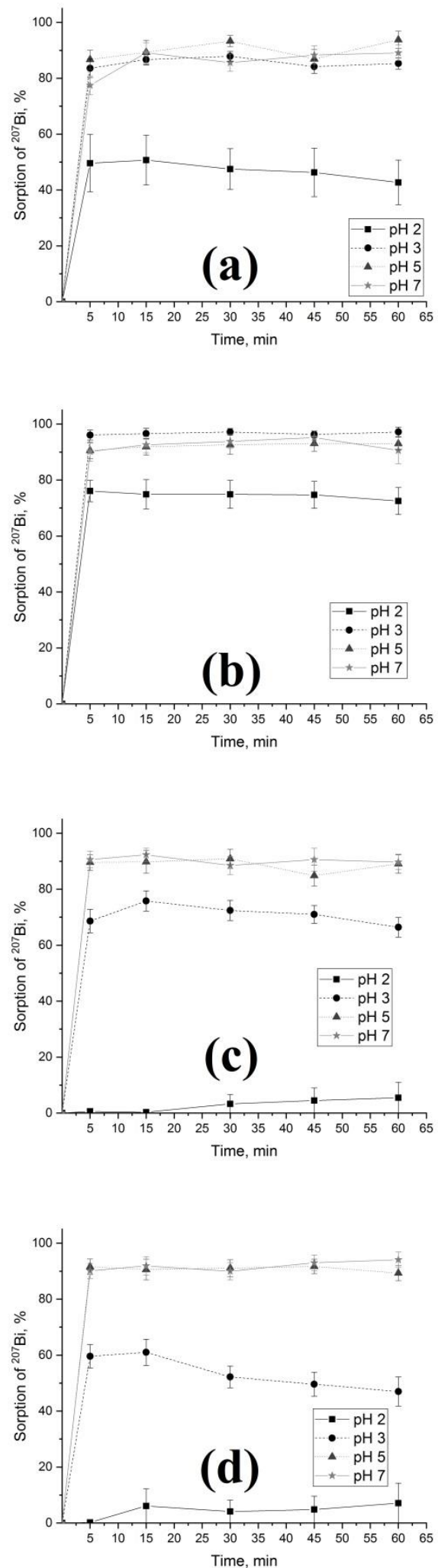

Figure 2. Sorption of ${ }^{207} \mathrm{Bi}$ (III) onto (a) ND, (b) oxND, (c) MWCNT, and (d) hydMWCNT from aqueous solutions at $25^{\circ} \mathrm{C}$ and $100 \mu \mathrm{g} / \mathrm{mL}$ of CNMs. 


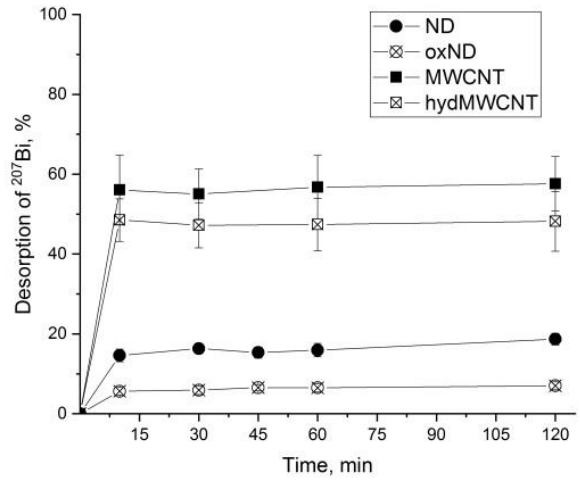

Figure 3. Desorption of ${ }^{207} \mathrm{Bi}(\mathrm{III})$ from $\mathrm{CNMs}(100 \mu \mathrm{g} / \mathrm{mL})$ in FBS medium at $37^{\circ} \mathrm{C}$.

MWCNT and hydMWCNT show less binding of ${ }^{207} \mathrm{Bi}$ and desorb about $50 \%$ of the radionuclide for the same time.

The results of studying the desorption of $207 \mathrm{Bi}$ from ND and oxND in FBS show that oxidation of ND (that is, the formation of more carboxyl groups on the surface, see Table 1) promotes stronger retention of ${ }^{207} \mathrm{Bi}$ on the surface. As for MWCNT and hydMWCNT, hydrogenation of MWCNT leads to a slight decrease in desorption of ${ }^{207} \mathrm{Bi}$; at the same time, the time-stable value of desorption on these samples probably indicates the existence of various mechanisms of interaction of 207Bi with them.

Thus, the oxND showed the highest resistance to desorption of ${ }^{207} \mathrm{Bi}$ among the studied CNMs during $2 \mathrm{~T}_{1 / 2}$ of ${ }^{212} \mathrm{Bi}$ or $3 \mathrm{~T}_{1 / 2}$ of ${ }^{213} \mathrm{Bi}$. In addition to the study of desorption in FBS in this work, we have previously shown the stability of the Bi(III)@oxND conjugate in $0.9 \% \mathrm{NaCl}$, PBS, and a solution of $40 \mathrm{~g} / \mathrm{L}$ bovine serum albumin in PBS at $37^{\circ} \mathrm{C}$ [34].

\subsection{Cytotoxicity of studied CNMs}

In the standard MTT test, the $\mathrm{LC}_{50}$ values for ND, oxND, MWCNT and hydMWCNT were determined to be outside of the studied concentration range, i.e. > 200 $\mu \mathrm{g} / \mathrm{mL}$ for both healthy and leukemic cells. The obtained values are consistent with the literature data on the cytotoxicity of ND [43] and MWCNT [44]. All these data together with sorption and desorption values make it possible to consider oxND as a promising carrier of these bismuth isotopes for further in vivo experiments and the creation of RPs.

\section{CONCLUSION}

In the present work, ND, MWCNT and their oxidized (oxND) and hydrogenated (hydMWCNT) derivatives were studied as sorbents for Bi(III) (using ${ }^{207} \mathrm{Bi}$ isotope) as a part for further potential RPs. It was shown that ND and oxND sorb more than $80 \%$ of $207 \mathrm{Bi}$ at $\mathrm{pH}_{3}$ to 7 , while the sorption onto oxND is $10 \%$ higher (not less than $95 \%$ ), which indicates a positive effect of the amount of carboxyl groups on sorption. In addition, the desorption of ${ }^{207} \mathrm{Bi}$ in the FBS medium for oxND is 5 \% for $120 \mathrm{~min}$, while for ND it is $15 \%$ for the same time. MWCNT and hydMWCNT sorb more than $85 \%$ of ${ }^{207} \mathrm{Bi}$ at $\mathrm{pH} 5$ to 7 ; however, the desorption from these CNMs reaches $50-60 \%$ in $5 \mathrm{~min}$. Thus, among the studied CNMs, oxND is promising for the creation of RPs based on it according to sorption and desorption values.

Acknowledgements: The study was funded by Russian Science Foundation, project №18-13-00413.

\section{REFERENCES}

1. L. Zhang, F.X. Gu, J.M. Chan, A.Z. Wang, R.S. Langer, O.C. Farokhzad, "Nanoparticles in medicine: therapeutic applications and developments," Educ. Policy. Anal. Arch., vol. 8, no. 5, pp. 761-769, Oct. 2007. http://doi.org/10.1038/sj.clp

2. S.J. Klaine, P.J.J. Alvarez, G.E. Batley, T.F. Fernandes, R.D. Handy, D.Y. Lyon, S.M.M.J. McLaughlin, J.R. Lead, "Nanomaterials in the environment: behavior, fate, bioavailability, and effects," Environ. Toxicol. Chem., vol. 27, no. 9, pp. 1825-1851, Nov. 2008

http://doi.org/10.1897/08-090.1

3. A. Albanese, P.S. Tang, W.C.W. Chan, "The Effect of nanoparticle size, shape, and surface chemistry on biological systems," Annu. Rev. Biomed. Eng., vol. 14, pp. 1-16, Apr. 2012.

http://doi.org/10.1146/annurev-bioeng-071811150124

4. E. Katz, I. Willner "Integrated nanoparticlebiomolecule hybrid systems: synthesis, properties, and applications", Angew. Chemie. Int. Ed., vol. 43, no. 45, pp. 6042-6108, Nov. 2004.

http://doi.org/10.1002/anie.200400651

5. F.E. Escorcia, M.R. McDevitt, C.H. Villa, D.A. Scheinberg, "Targeted nanomaterials for radiotherapy", Nanomedicine, vol. 2, no. 3 pp. 805-815, Dec. 2007. http://doi.org/10.2217/17435889.2.6.805

6. M.A. Elkodous, G.S. El-Sayyad, I.Y. Abdelrahman H.S. El-Bastawisy, A.E. Mohamed, F.M. Mosallam, H.A. Nassere, M. Gobara, A. Baraka, M.A. Elsayed, A.I. El-Batal, "Therapeutic and diagnostic potential of nanomaterials for enhanced biomedical applications," Colloids Surfaces B: Biointerfaces, vol. 180, pp. 411-428, Aug. 2019.

http://doi.org/10.1016/j.colsurfb.2019.05.008

7. G. Seeta Rama Raju, L. Benton, E. Pavitra, J.S. Yu, "Multifunctional nanoparticles: Recent progress in cancer therapeutics", Chem. Commun., vol. 51, pp. 13248-13259, Jul. 2015 http://doi.org/10.1039/c5cc04643b

8. D.-E. Lee, H. Koo, I.-C. Sun, J.H. Ryu, K. Kim, I.C. Kwon, "Multifunctional nanoparticles for multimodal imaging and theragnosis," Chem. Soc. Rev., vol. 41, pp. 2656-2672, Dec. 2011. http://doi.org/10.1039/C2CS15261D

9. M. Varani, F. Galli, S. Auletta, A. Signore, "Radiolabelled nanoparticles for cancer diagnosis," Clin. Transl. Imag., vol. 6, pp. 271-292, May 2018. http://doi.org/10.1007/s40336-018-0283-x

10. A.M. Grimaldi, M. Incoronato, M. Salvatore, A. Soricelli, "Nanoparticle-based strategies for cancer immunotherapy and immunodiagnostics," Nanomedicine, vol. 12, pp. 2349-2365, Sep. 2017. http://doi.org/10.2217/nnm-2017-0208 
11. J. Ge, Q. Zhang, J. Zeng, Z. Gu, M. Gao, "Radiolabeling nanomaterials for multimodality imaging: New insights into nuclear medicine and cancer diagnosis," Biomaterials, vol. 228, article no. $119553,(2020)$.

http://doi.org/10.1016/j.biomaterials.2019.119553

12. B. Kateb, K. Chiu, K.L. Black, V. Yamamoto, B. Khalsa J.Y. Ljubimova, H. Ding, R.Patil, J. A. Portilla-Arias, M. Modo, D.F. Moore, K. Farahani, M.S. Okun, N. Prakash, J. Nemani, D. Ahdoot, W. Grundfest, S. Nikzad, J.D. Heiss, "Nanoplatforms for constructing new approaches to cancer treatment, imaging, and drug delivery: What should be the policy?," Neuroimage, vol. 54, pp. S106-S124, Jan. 2011.

http://doi.org/10.1016/j.neuroimage.2010.01.105

13. S. Rojas, J.D. Gispert, R. Martín, S. Abad, C. Menchon, D. Pareto, V.M. Victor, M. Alvaro, H. Garcia, J.R. Herance, "Biodistribution of aminofunctionalized diamond nanoparticles. In vivo studies based on ${ }^{18} \mathrm{~F}$ radionuclide emission", ACS Nano, vol 5, no. 2, pp. 5552-5559, Jun 2011.

http://doi.org/10.1021/nn200986z

14. L. Chen, X. Zhong, X. Yia, M. Huang, P.Ning, T.Liu, C. Ge, Z. Chai, Z.Liu, K.Yang, "Radionuclide ${ }^{131} \mathrm{I}$ labeled reduced graphene oxide for nuclear imaging guided combined radio- and photothermal therapy of cancer," Biomaterials, vol. 66, pp. 21-28, Oct. 2015. http://doi.org/10.1016/j.biomaterials.2015.06.043

15. G.S. Suri, A. Kaur, T. Sen, "A recent trend of drugnanoparticles in suspension for the application in drug delivery," Nanomedicine, vol. 11, no. 21, Oct. 2016

http://doi.org/10.2217/nnm-2016-0238

16. S. Goel, C.G. England, F. Chen, W. Cai, "Positron emission tomography and nanotechnology: A dynamic duo for cancer theranostics," Adv. Drug Deliv. Rev. vol. 113, pp. 157-176, Apr. 2017. http://doi.org/10.1016/j.addr.2016.08.001

17. H. Hong, Y. Zhang, J.W. Engle, T.R. Nayak, C.P. Theuer, R.J. Nickles, T.E. Barnhart, W.Cai, "In vivo targeting and positron emission tomography imaging of tumor vasculature with ${ }^{66} \mathrm{Ga}-$ labeled nanographene," Biomaterials, vol. 33, pp. 4147-4156, Jun. 2012.

http://doi.org/10.1016/j.biomaterials.2012.02.031

18. K. Yang, L. Feng, H. Hong, W. Cai, Z. Liu "Preparation and functionalization of graphene nanocomposites for biomedical applications," Nat. Protoc., vol. 8, pp. 2392-2403, Nov. 2013.

http://doi.org/10.1038/nprot.2013.146

19. S. Shi, C. Xu, K. Yang, S. Goel, H. F. Valdovinos, H. Luo, E.B. Ehlerding, C.G. England, L. Cheng, F. Chen, R.J. Nickles, Z. Liu, W. Cai, "Chelator-free radiolabeling of nanographene: breaking the stereotype of chelation," Angew. Chemie Int. Ed., vol. 56, no. 11, pp. 2889-2892, Feb. 2017.

http://doi.org/10.1002/anie.201610649

20. M.R. McDevitt, D. Chattopadhyay, B.J. Kappel, J.S. Jaggi, S.R. Schiffman, C. Antczak, J.T. Njardarson, R. Brentjens, D.A. Scheinberg, "Tumor targeting with antibody-functionalized, radiolabeled carbon nanotubes," J. Nucl. Med., vol. 48, no. 7, pp.1180-1189, July 2007.

http://doi.org/10.2967/jnumed.106.039131

21. M. Swierczewska, K.Y. Choi, E.L. Mertz, X. Huang, F. Zhang, L. Zhu, H.Y. Yoon, J.H. Park, A. Bhirde, S. Lee, X. Cnen, "A facile, one-step nanocarbon functionalization for biomedical applications," Nano Lett., vol. 12, no. 7, pp. 3613-3620, Jun 2012. http://doi.org/10.1021/nl301309g

22. S.Y. Hong, G. Tobias, K.T. Al-Jamal, B. Ballesteros, H. Ali-Boucetta, S. Lozano-Perez, P.D. Nellist,
R.B. Sim, C. Finucane, S. J. Mather, M.L.H. Green, K. Kostarelos, B.G. Davis, "Filled and glycosylated carbon nanotubes for in vivo radioemitter localization and imaging," Nat. Mater., vol. 9, pp. 485-490, May 2010.

http://doi.org/10.1038/nmat2766

23. A. Ruggiero, C.H. Villa, J.P. Holland, S.R. Sprinkle, C. May, J.S. Lewis, D.A. Scheinberg, M. R. McDevitt, "Imaging and treating tumor vasculature with targeted radiolabeled carbon nanotubes," Int. J. Nanomedicine, vol.5, pp. 783-802, Sep. 2010.

http://doi.org/10.2147/IJN.S13300

24. B.T. Cisneros, J.J. Law, M.L. Matson, A. Azhdarinia E.M. Sevick-Muraca, L.J. Wilson, "Stable confinement of positron emission tomography and magnetic resonance agents within carbon nanotubes for bimodal imaging," Nanomedicine, vol. 9, no. 16, pp. 2499-2509, Mar. 2014.

http://doi.org/10.2217/nnm.14.26

25. M.L. Matson, C.H. Villa, J.S. Ananta, J.J. Law, D.A. Scheinberg, L.J. Wilson, "Encapsulation of particle-emitting ${ }^{225 \mathrm{Ac}^{3}}{ }^{+}$ions within carbon nanotubes," J. Nucl. Med., vol. 56, no.6, pp. 897-900, Jun. 2015.

http://doi.org/10.2967/jnumed.115.158311

26. H. Zhao, Y. Chao, J. Liu, J. Huang, J. Pan, W. Guo, J. Wu, M. Sheng, K. Yang, J. Wang, Z. Liu, "Polydopamine coated single-walled carbon nanotubes as a versatile platform with radionuclide labeling for multimodal tumor imaging and therapy," Theranostics, vol. 6, no. 11, pp. 1833-1843, Jun 2015. http://doi.org/10.7150/thno.16047

27. J. Elgqvist, S. Frost, J.-P. Pouget, P. Albertsson, “The potential and hurdles of targeted alpha therapy clinical trials and beyond,"Front. Oncol., vol. 3, Jan. 2014.

http://doi.org/10.3389/fonc.2013.00324

28. Y-S Kim, M.W. Brechbiel, "An overview of targeted alpha therapy," Tumor Biol., vol. 33, pp. 573-590, Dec. 2011.

http://doi.org/10.1007/s13277-011-0286-y

29. B.L. Garashchenko, V.A. Korsakova, R.Y. Yakovlev, "Radiopharmaceuticals based on alpha emitters: preparation, properties, and application," Phys. At Nucl., vol. 81, pp. 1515-1525, Mar. 2019.

http://doi.org/10.1134/S1063778818100071

30. B.L. Garashchenko, N.N. Dogadkin, N.E. Borisova, R.Y. Yakovlev, "Sorption of $223 \mathrm{Ra}$ and $211 \mathrm{~Pb}$ on modified nanodiamonds for potential application in radiotherapy," J. Radioanal. Nucl. Chem., vol. 318, pp. 2415-2423, Nov. 2018.

http://doi.org/10.1007/s10967-018-6330-2

31. K.B. Hartman, D.K. Hamlin, D.S. Wilbur, L.J. Wilson, “211AtCl@US-tube nanocapsules: A new concept in radiotherapeutic-agent design," Small, vol. 3, no. 9, pp. 1496-1499, Sep. 2007.

http://doi.org/10.1002/smll.200700153

32. A. Ruggiero, C.H. Villa, J.P. Holland, S.R. Sprinkle, C. May, J. Lewis, D. Scheinberg, M.R. McDevitt, "Imaging and treating tumor vasculature with targeted radiolabeled carbon nanotubes," Int. J. Nanomedicine, vol. 5, pp. 783-802, Sep. 2010. http://doi.org/10.2147/IJN.S13300

33. S. Zhang, K. Yang, L. Feng, Z. Liu, "In vitro and in vivo behaviors of dextran functionalized grapheme," Carbon, vol. 49, no. 12, pp. 4040-4049, Oct. 2011. http://doi.org/10.1016/j.carbon.2011.05.056

34. A.G. Kazakov, B.L. Garashchenko, R.Y. Yakovlev, S.E. Vinokurov, S.N. Kalmykov, B.F. Myasoedov, “An experimental study of sorption/desorption of selected radionuclides on carbon nanomaterials: a quest for possible applications in future nuclear medicine," Diam. Relat. Mater., vol. 104, no. 107752, Apr. 2020. 
http://doi.org/10.1016/j.diamond.2020.107752

35. S. Hassfjell, M.W. Brechbiel, "The development of the $\alpha$-particle emitting radionuclides ${ }^{212} \mathrm{Bi}$ and ${ }^{213} \mathrm{Bi}$, and their decay chain related radionuclides, for therapeutic applications," Chem. Rev., vol. 101, no 7, pp. 2019-2036, Jun. 2001.

http://doi.org/10.1021/crooo118y

36. A. Morgenstern, C. Apostolidis, C. Kratochwil, M. Sathekge, L. Krolicki, F. Bruchertseifer, "An overview of targeted alpha therapy with 225-actinium and 213-bismuth," Curr. Radiopharm., vol. 11, no. 3, pp. 200-208, Mar. 2018. http://doi.org/10.2174/187447101166618050210452 4

37. M.G. Ferrier, V. Radchenko, D.S., "Radiochemical aspects of alpha emitting radionuclides for medical application", Radiochim. Acta, vol. 107, no. 9-11, pp. 1065-1085, May 2019.

http://doi.org/10.1515/ract-2019-0005

38. A. Morgenstern, C. Apostolidis, F. Bruchertseifer "Supply and clinical application of actinium-225 and bismuth-213," Semin. Nucl. Med., vol. 50, pp. 119-123, Mar. 2020.

http://doi.org/10.1053/j.semnuclmed.2020.02.003

39. P.J. Blower, "A nuclear chocolate box: The periodic table of nuclear medicine," Dalt. Trans., vol. 44 (11), pp. 4819-4844, Oct. 2015.

http://doi.org/10.1039/c4dto2846e

40. M. Makvandi, E. Dupis, J.W. Engle, F.M. Nortier, M.E. Fassbender, S. Simon, E.R. Birnbaum, R.W. Atcher, K.D. John, O. Rixe, J.P. Norenberg,
"Alpha-emitters and targeted alpha therapy in oncology: from basic science to clinical investigations," Target. Oncol., vol. 13, pp. 189-203, Feb. 2018.

http://doi.org/10.1007/s11523-018-0550-9

41. A.G. Kazakov, B.L. Garashchenko, M.K. Ivanova, S.E. Vinokurov, B.F. Myasoedov, "Carbon nanomaterials for sorption of ${ }^{68} \mathrm{Ga}$ for potential using in positron emission tomography," Nanomaterials, vol. 10, no. 6, pp.1090-1-13, Jun 2020. http://doi.org/10.3390/nano10061090

42. A.G. Kazakov, B.L. Garashchenko, R.Yu. Yakovlev, S.E. Vinokurov, S.N. Kalmykov, B.F. Myasoedov, "Generator of Actinium-228 and a Study of the Sorption of Actinium by Carbon Nanomaterials," Radiochemistry, vol. 62, no. 5, pp. 592-598, Oct. 2020.

http://doi.org/10.1134/S1066362220050057

43. M. Ibrahim, Y. Xue, M. Ostermann, A. Sauter D. Steinmueller-Nethl, S. Schweeberg, A. Krueger, M.R. Cimpan, K. Mustafa, "In vitro cytotoxicity assessment of nanodiamond particles and their osteogenic potential," J. Biomed. Mater. Res. Part. A, vol. 106, pp. 1697-1707, Feb. 2018.

http://doi.org/10.1002/jbm.a.36369

44. L. Zhou, H.J. Forman, Y. Ge, J. Lunec "Multi-walled carbon nanotubes: A cytotoxicity study in relation to functionalization, dose and dispersion," Toxicol. Vitr., vol. 42, no. 4, pp. 292-298, Aug. 2017.

http://doi.org/10.1016/j.tiv.2017.04.027 